\title{
Enzyme-Catalyzed Synthesis of 2-Azido-2-deoxy-D-glucose under Catalysis by Recombinant Cellobiose Phosphorylase (CeP)
}

\author{
B. LUbura ${ }^{1}$, N. Gabra ${ }^{1}$, P. StarkL ${ }^{2}$, H. Viernstein ${ }^{1}$, F. M. Unger ${ }^{1}$ \\ ${ }^{1}$ Department of Pharmaceutical Technology and Biopharmaceutics, University of Vienna, Althanstrasse 14, \\ 1090 Vienna, Austria \\ ${ }^{2}$ Department of Pathophysiology, Medical University of Vienna, Waehringer Guertel 18-20, 1090 Vienna, \\ Austria \\ E-mail: borjana.lubura@univie.ac.at (B. Lubura)
}

Sci Pharm. 2010; 78: 707

doi:10.3797/scipharm.cespt.8.PPAT18

The use of enzyme-catalyzed reactions for the synthesis of sugar substrates represents a more desirable approach in terms of "green chemistry". As the azidonitratization reaction of cellobial furnishes the 2-azido-2-deoxycellobiose stereospecifically, we have prepared 2-azido-2-deoxyglucose from 2-azido2-deoxycellobiose using recombinant cellobiose phosphorylase (CeP) from Clostridium thermocellum NCIMB 10682 [1]. This enzyme catalyzes the reversible phosphorolysis of cellobiose to form $\alpha$-D-glucose and $\alpha$-D-Glucose1-phosphate with inversion of the anomeric configuration (Scheme 1) [2].

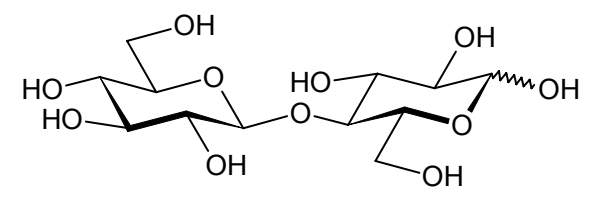

Cellobiose

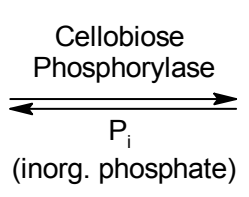

D-Glucose-1-phosphate

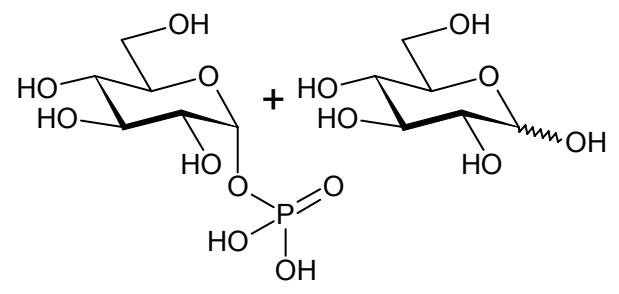

D-Glucose

2-Azido-2-deoxycellobiose is cleaved quantitatively by the action of cellobiose phosphorylase and is separated from glucose 1-phosphate by filtration through DEAE-cellulose. In this manner, we have demonstrated that the substitution of the hydroxyl group by an azido group in position 2 of the reducing cellobiose moiety is tolerated by the recombinant CeP.

[1] Wong CH, Koeller KM. Enzymes for chemical synthesis. Nature. 2001; 409: 232-240. doi:10.1038/35051706

[2] David BG, Fairbanks AJ. Carbohydrate Chemistry. Oxford University Press, 2002 